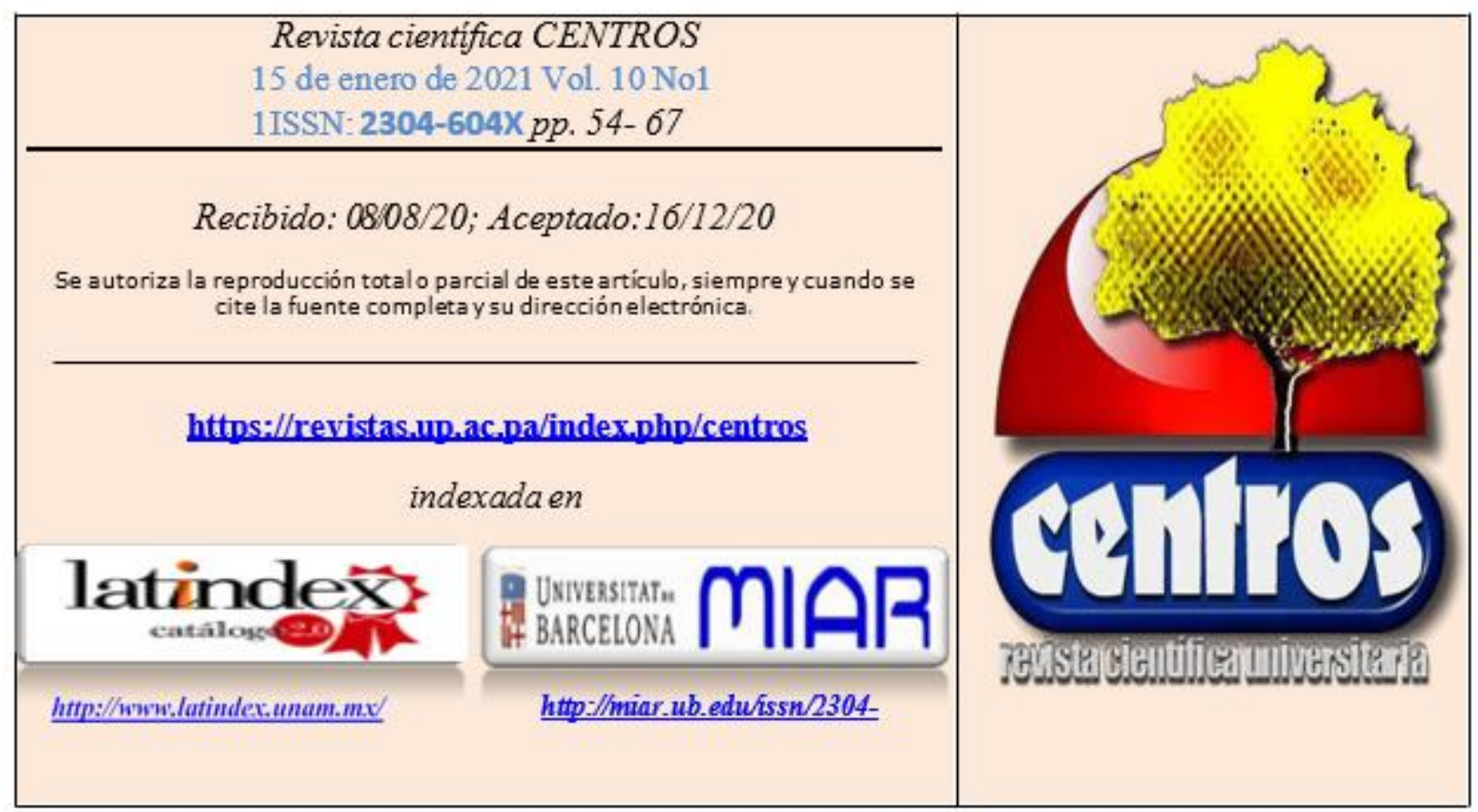

\title{
COMPARACIÓN DE DOS SISTEMAS DE TRATAMIENTO ANAERÓBICOS DE AGUAS RESIDUALES DE CARACTERÍSTICAS HOMOGÉNEAS PARA ESCUELAS SIN SISTEMA DE TRATAMIENTO
}

\section{COMPARISON OF TWO SYSTEMS OF ANAEROBIC TREATMENT FOR WATER MANAGEMENT OF SIMILAR CARACTERISTICS IN SCHOOL WITHOUT WASTEWATER TREATMENT SYSTEM}

\author{
Irving Isaac Isaza Santos \\ Universidad de Panamá/ https://orcid.org/0000-0002-4029-0992
}

irving.isaza@up.ac.pa

Freddy González

Universidad Tecnológica de Panamá/ https://orcid.org/0000-0002-8582-9306 fredy.gonzalez@utp.ac.pa

Yarelys Gómez

Asesora e Investigadora Independiente/ https://orcid.org/0000-0003-0226-1100 galvezyarelys@gmail.com 


\section{Resumen}

En las escuelas de la República de Panamá que se encuentran en áreas rurales y sitios que no cuentan con sistemas de alcantarillado municipal en la actualidad muchos de los pliegos de cargos y contratista de proyectos hacen referencia al sistema de Tanque Séptico como el sistema de tratamiento primario más versátil en cuanto al manejo de plantas de tratamiento aguas residuales (PTAR) y económico en cuanto a construcción y mantenimiento. En este artículo se realiza una modelación comparativa entre el sistema de tanque séptico y un reactor UASB para la PTAR de escuelas, destacando la efectividad del tratamiento anaeróbico (Lozada, 2012), (Salazar-Larrota, Luis, et al, 2009) (Lorenzo y Obaya, 2006), además de su viabilidad económica en cuanto a costos de construcción y mantenimiento lo cual hace considerar implementar PTAR con sistema de reactor UASB en ambientes tropicales (Conil, 2001).

Palabras clave: Contaminación del agua, tratamiento de aguas residuales, tratamiento anaeróbico, tanque séptico, reactor UASB, efluentes.

\section{Abstract}

In the schools of the Republic of Panama that are located in rural areas and sites that do not have municipal sewerage systems at present, many of the tender documents and project contractors refer to the Septic Tank system as the primary treatment system more versatile in terms of wastewater management and more economical in terms of construction and maintenance. This article make a comparative modeling between Septic Tank system and a UASB reactor to build wastewater treatment system in schools, highlighting the effectiveness for anaerobic treatment (Lozada, 2012), (Salazar-Larrota, Luis, et al, 2009) (Lorenzo y Obaya, 2006), furthermore of the economic viability in terms of cost to build and maintenance to take the option to improve wastewater treatment system with UASB reactor in tropical environments (Conil, 2001). 
Keywords: Water pollution, wastewater treatment system, anaerobic treatment, septic tank, UASB reactor, effluents.

\section{Introducción}

Los procesos de tratamientos anaerobios se producen en ausencia de oxígeno. En los mismos se desarrollan bacterias las cuales hidrolizan y fermentan los compuestos de complejos a simples.

Los tanques sépticos por lo general se utilizan para el tratamiento de aguas residuales de característica familiar (aguas homogéneas) Sus principales ventajas tenemos: Es apropiado para comunidades rurales, Su limpieza no es frecuente, Tiene bajo costo de construcción y operación, No se requiere de una mano de obra especializada para su operación y el mínimo grado de dificultad para el mantenimiento si se cuenta con infraestructura de remoción de lodos. Sus desventajas No son recomendables para más de 350 personas, Se limita si el terreno no tiene la capacidad de infiltración, requiere facilidades para la remoción de lodos.

Los reactores UASB son sistemas de tratamiento anaerobios más eficiente ya que tienen una alta eficiencia en la remoción de materia orgánica sin la necesidad que exista grandes tiempos de retención dentro de la misma. Su principal ventaja consiste que no requiere ningún tipo de soporte para retener la biomasa. Lo que implica un ahorro importante. Su principal desventaja es el proceso de arranque ya que comienza de una manera lenta (en algunos casos hasta 6 meses) en cuanto a las de diseño hay que tener controlada las variables hidráulicas (velocidad ascensional, velocidad de paso a través del separador de fases, dispositivo de entrada y salida).

\section{Materiales y Métodos}

Para comenzar a realizar este análisis comparativo entre el Tanque Séptico vs Reactor UASB se va a diseñar (dimensionamiento) los sistemas primarios para un colegio 
con una población de 600 habitantes que involucra estudiantes, profesores y administrativos en el plantel.

Para el tanque séptico se procedió a calcular las principales variables de diseño según el manual de la Organización Panamericana de la Salud como son el tiempo de retención 2 días, el consumo per cápita según el Instituto de acueductos y alcantarillados nacionales para zonas rurales es de 80 galones/persona por día, un valor del $80 \%$ que es la contribución de las aguas servidas, el cálculo del factor de Máxima $F$ ( $F=6.46$ hab$0.152)$.

Una vez conocida las variables se procedió al cálculo del caudal medio, con este caudal medio y el tiempo de retención de 2 días se obtuvo el volumen del sedimentador, luego se calculó el volumen de digestión y almacenamiento de lodos para un periodo de 8 años de limpieza una vez hecho esto se procedió a que este espacio fuera mayor al volumen de lodos producidos que para un clima cálido la cantidad de lodos producidos por habitante y por año 40 litros/hab-año.

La metodología para el diseño del paralelepípedo del tanque séptico, se considera una profundidad de $2.5 \mathrm{~m}$ y una relación de largo/ancho de 3:1.

Tabla 1. Comparación entre Diseño del Tanque Séptico y el Reactor UASB.

\begin{tabular}{|c|c|c|}
\hline Variables & $\begin{array}{c}\text { Valores del Tanque } \\
\text { Séptico }\end{array}$ & Valores del reactor \\
\hline Población & 600 personas & 600 personas \\
\hline $\begin{array}{c}\text { Tiempo de } \\
\text { retención }\end{array}$ & 2 días \\
\hline $\begin{array}{c}\text { Consumo per } \\
\text { cápita }\end{array}$ & $80 \mathrm{gal} /$ persona/día \\
\hline $\begin{array}{c}\text { Contribución de } \\
\text { aguas servidas } \\
\text { Factor de máxima }\end{array}$ & $80 \%$ & 80 gal/persona/día \\
\hline
\end{tabular}




\begin{tabular}{|c|c|c|}
\hline $\begin{array}{c}\text { Profundidad del } \\
\text { tanque }\end{array}$ & 2.5 metros & 2.5 metros \\
\hline $\begin{array}{c}\text { Tiempo de } \\
\text { limpieza del tanque }\end{array}$ & 8 años & \\
\hline Lodos producidos & 40 l/persona/año & \\
\hline DQO afluente & & $380 \mathrm{mg} / \mathrm{l}$ \\
\hline Relación & & 1.875 \\
DQO/DBO5 & & \\
\hline
\end{tabular}

Fuente: Los Autores

Para el caso del reactor UASB se utilizaron las mismas variables como lo son la misma población, el consumo per cápita, la contribución de las aguas servidas y el cálculo del factor de máxima. Las variables a considerar fueron la demanda química de oxígeno y la respectiva relación que tiene con la demanda bioquímica de oxígeno, todo esto según norma DGNTI-COPANIT 39-2000 Ministerio de Comercio e Industrias Dirección General de Normas y Tecnología Industrial.

Con estas variables el caudal medio del Tanque Séptico es igual al del reactor, se procede al cálculo de los caudales Máximo Diario y Horario para zonas rurales, luego se calcula la carga del afluente medio. Una vez hecho esto con el caudal medio y el tiempo de retención se procedió a calcular el volumen total requerido para el reactor, en el mismo se hicieron las comparaciones de las variables hidráulicas como son las velocidades con las permisibles, luego con la misma altura que se usan para el tanque séptico determinar el área del reactor, se calcularon los tubos difusores y el área del separador gas-solidolíquido que es el dispositivo más importante en el reactor.

Ha existido una amplia discusión en la implementación de los reactores UASB para sistema de tratamiento de aguas residuales, del cual podemos resumir en el siguiente cuadro. 
Tabla 2. Ventajas y Desventajas en el Reactor UASB.

\begin{tabular}{|l|l|}
\hline \multicolumn{1}{|c|}{ Ventajas } & \multicolumn{1}{|c|}{ Desventajas } \\
\hline Bajo consumo eléctrico. & El comienzo del proceso es lento y \\
Puede producir calor y electricidad. & requiere de un período de 8 a 12 \\
Baja producción de fango. & semanas. \\
Apropiado para aguas extremadamente & El proceso es sensible a la presencia \\
contaminadas. & de compuestos tóxicos. \\
La producción de lodos estabilizados en & La reducción de bacterias patógenas es \\
exceso es mínima y fácil de drenar & relativamente baja. \\
hasta de 30 a $40 \%$ y, por tanto, los & \\
costos & \\
de tratamiento del lodo y su & \\
transportación posterior son & \\
relativamente bajos. & \\
Se pueden aplicar altas cargas & \\
hidráulicas y orgánicas con eficiencias & \\
aceptables. & \\
El reactor necesita poco espacio. & \\
Los lodos anaerobios adaptados \\
pueden mantenerse sin alimentación \\
por largos \\
períodos de tiempo, por lo que el \\
proceso resulta muy adecuado para las \\
industrias que trabajan de forma cíclica. \\
Su construcción no es compleja y los \\
costos de operación y mantenimiento \\
son relativamente bajos.
\end{tabular}

Fuente: Lorenzo y Obaya, 2006. 


\section{Resultados}

A continuación, se presenta los cuadros de diseño de dimensionamiento del Tanque Séptico y el reactor UASB. En el cuadro de resultados del tanque séptico podemos observar el cálculo del caudal medio $=354.64 \mathrm{~m}^{3} / \mathrm{s}$, con este valor se obtuvo el valor de volumen del sedimentador $709.29 \mathrm{~m}^{3}$ y el volumen del digestor y área de almacenamiento de $819.84 \mathrm{~m}^{3}$ con esto se obtiene un volumen total de $1629.13 \mathrm{~m}^{3}$

Tabla 3. Resultados del dimensionamiento entre el Tanque Séptico y el Reactor UASB.

\begin{tabular}{|c|c|c|}
\hline Variables & Valores del Tanque & Valores del reactor \\
\hline Caudal medio & $354.64 \mathrm{~m}^{3} /$ día & $354.64 \mathrm{~m}^{3} / \mathrm{día}$ \\
\hline Largo & $44.25 \mathrm{~m}$ & $8 \mathrm{~m}$ \\
\hline Ancho & $14.75 \mathrm{~m}$ & $8 \mathrm{~m}$ \\
\hline Profundidad & $2.5 \mathrm{~m}$ & $2.5 \mathrm{~m}$ \\
\hline Volumen total & $1629.13 \mathrm{~m}^{3}$ & $160 \mathrm{~m}^{3}$ \\
\hline $\begin{array}{c}\text { Volumen del } \\
\text { sedimentador }\end{array}$ & $709.29 \mathrm{~m}^{3}$ & \\
\hline $\begin{array}{c}\text { Volumen de } \\
\text { digestión y } \\
\text { almacenamiento de lodos } \\
\text { Volumen de lodos } \\
\text { generados }\end{array}$ & $419.84 \mathrm{~m}^{3}$ & \\
\hline $\begin{array}{c}\text { Caudal máximo } \\
\text { diario }\end{array}$ & $468.48 \mathrm{~m}^{3}$ & $36.94 \mathrm{~m}^{3} / \mathrm{hora}$ \\
\hline $\begin{array}{c}\text { Caudal máximo } \\
\text { específico }\end{array}$ & & $59.12 \mathrm{~m}^{3} / \mathrm{hora}$ \\
\hline $\begin{array}{c}\text { Carga del afluente } \\
\text { medio }\end{array}$ & & 134.763 \\
\hline
\end{tabular}




\begin{tabular}{|c|c|c|}
\hline Cálculo de COV & & 1.0115 \\
& DQO/día \\
\hline Cálculo de CHV & & $2.667 \mathrm{~m} 3 /$ día \\
\hline Velocidad media & & $0.23 \mathrm{~m} / \mathrm{hora}$ \\
\hline $\begin{array}{c}\text { Velocidad máxima } \\
\text { específica }\end{array}$ & $0.923 \mathrm{~m} / \mathrm{hora}$ \\
\hline $\begin{array}{c}\text { Cantidad de } \\
\text { difusores }\end{array}$ & 27 \\
\hline Área del reactor & \\
\hline
\end{tabular}

Fuente: Los Autores

Con estas dimensiones y utilizando una relación 3:1 para el lado largo sobre ancho se obtuvo el dimensionamiento del Sistema primario obteniendo los siguientes valores: largo de $44.25 \mathrm{~m}$, ancho de $14.75 \mathrm{~m}$ y una profundidad de $2.50 \mathrm{~m}$.

Para los mismos valores de caudal medio $=354.64 \mathrm{~m}^{3} / \mathrm{s}$ con un valor de DQO homogéneo de $380 \mathrm{mg} / \mathrm{l}$ y un tiempo de retención de 9 horas obtenemos un volumen de Sistema primario de $160 \mathrm{~m}^{3}$ para un área de $64 \mathrm{~m}^{2}$ lo que representa un dimensionamiento con los siguientes valores: $\operatorname{largo}=8 \mathrm{~m}$, ancho $=8 \mathrm{~m}$ y una altura de $2.5 \mathrm{~m}$.

Con esto comparamos los valores de dimensiones, mientras un tanque séptico para la misma población requiere de $1629.13 \mathrm{~m}^{3}$ el reactor requiere de $160 \mathrm{~m}^{3}$ como Sistema de tratamiento primario el tanque séptico resulta 10.20 veces más grande que el reactor. 
Grafica 1.

Relación de dimensiones entre sistema de tanque séptico y reactor UASB

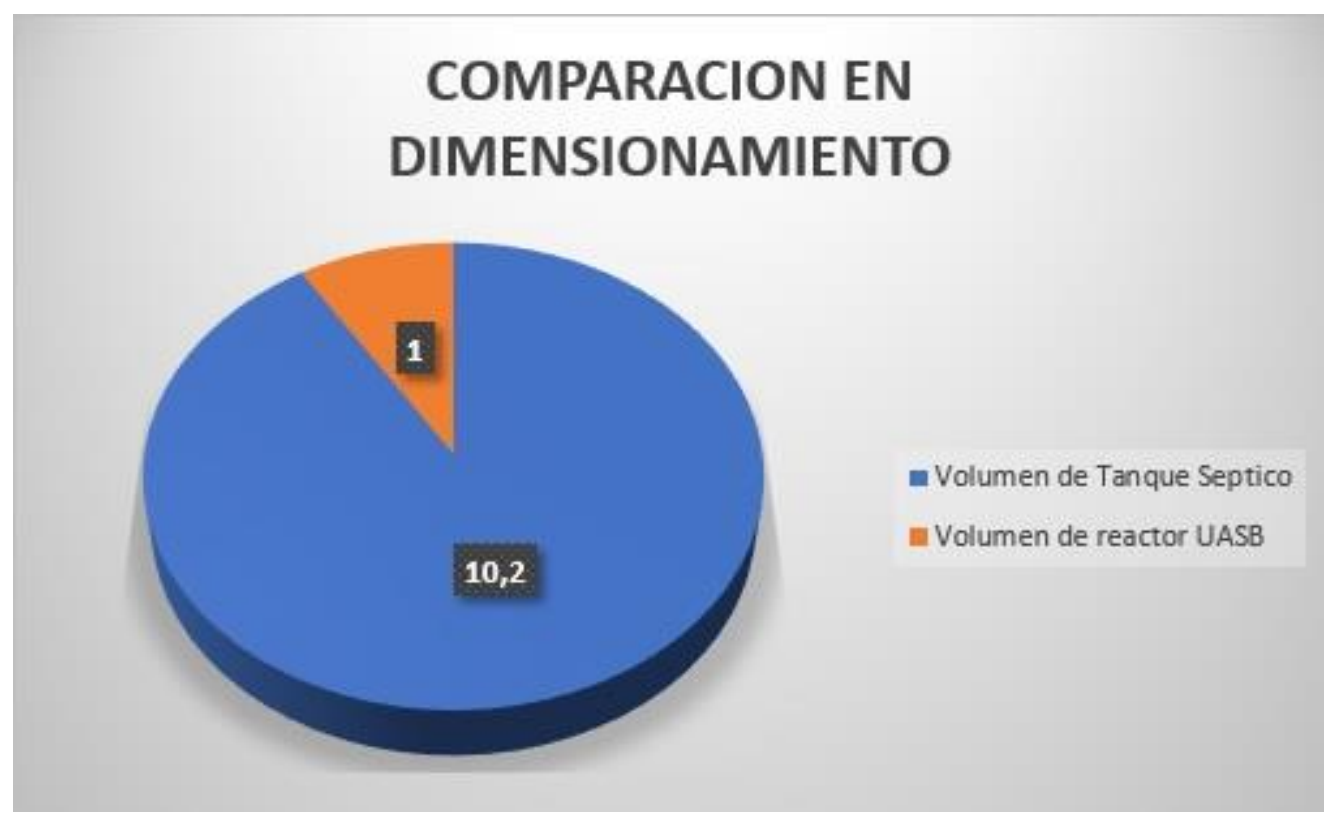

Fuente: Los Autores.

Si consideramos en la construcción un espesor constante de concreto de $0.25 \mathrm{~m}$, dentro de las paredes de contención para ambos sistemas, obtenemos los siguientes resultados.

Tabla 4. Comparación de volumen de concreto entre el sistema de Tanque Séptico y el Reactor UASB.

\begin{tabular}{|c|c|c|}
\hline $\begin{array}{c}\text { Volumen de } \\
\text { concreto }\end{array}$ & Tanque Séptico & Reactor UASB \\
\hline Fondo & $163.172 \mathrm{~m}^{3}$ & $16 \mathrm{~m}^{3}$ \\
\hline Paredes laterales & $55.313 \mathrm{~m}^{3}$ & $10 \mathrm{~m}^{3}$ \\
\hline $\begin{array}{c}\text { Paredes } \\
\text { transversales }\end{array}$ & $18.438 \mathrm{~m}^{3}$ & $10 \mathrm{~m}^{3}$ \\
\hline Tapa & $163.172 \mathrm{~m}^{3}$ & $16 \mathrm{~m}^{3}$ \\
\hline Total & $400.094 \mathrm{~m}^{3}$ & $52 \mathrm{~m}^{3}$ \\
\hline
\end{tabular}

Fuente: Los Autores 
Gráfica 2.

Relación en porcentajes de volumen de concreto en las partes del Tanque Séptico.

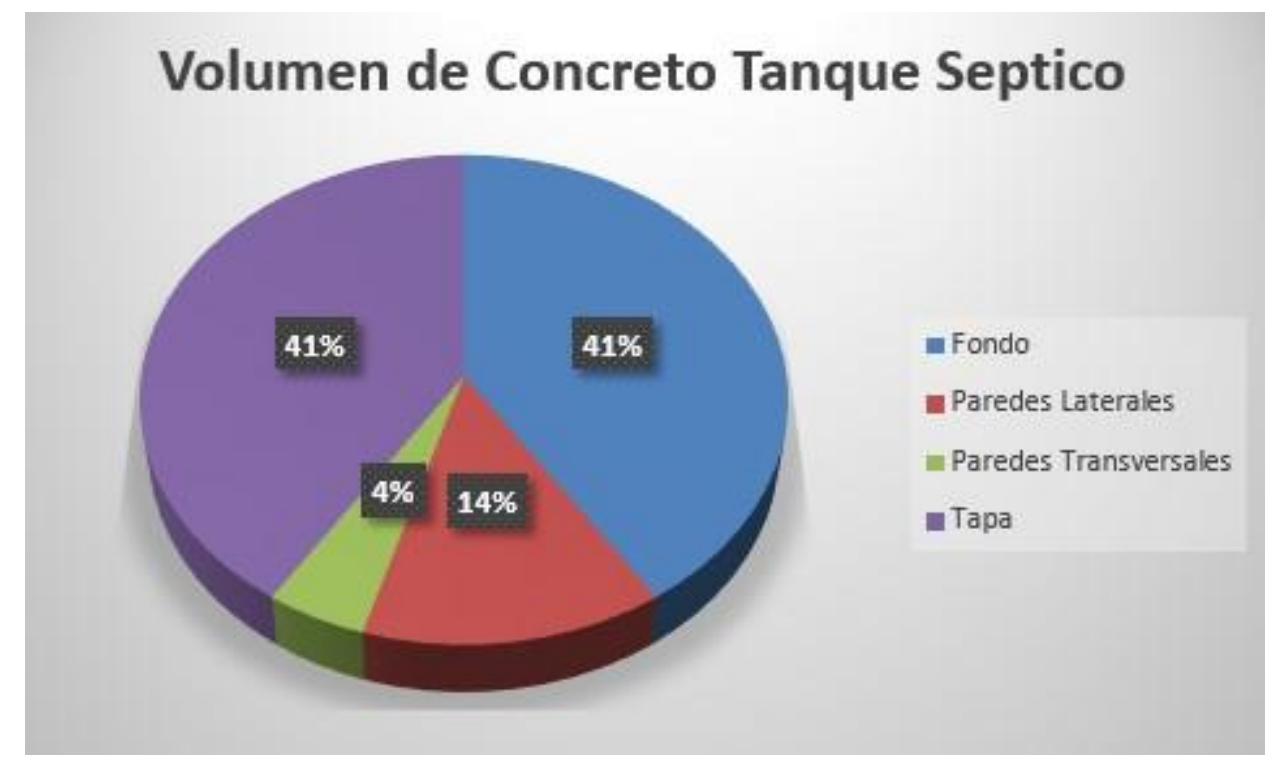

Fuente: Los Autores

Gráfica 3.

Relación en porcentajes de volumen de concreto en las partes del Reactor UASB.

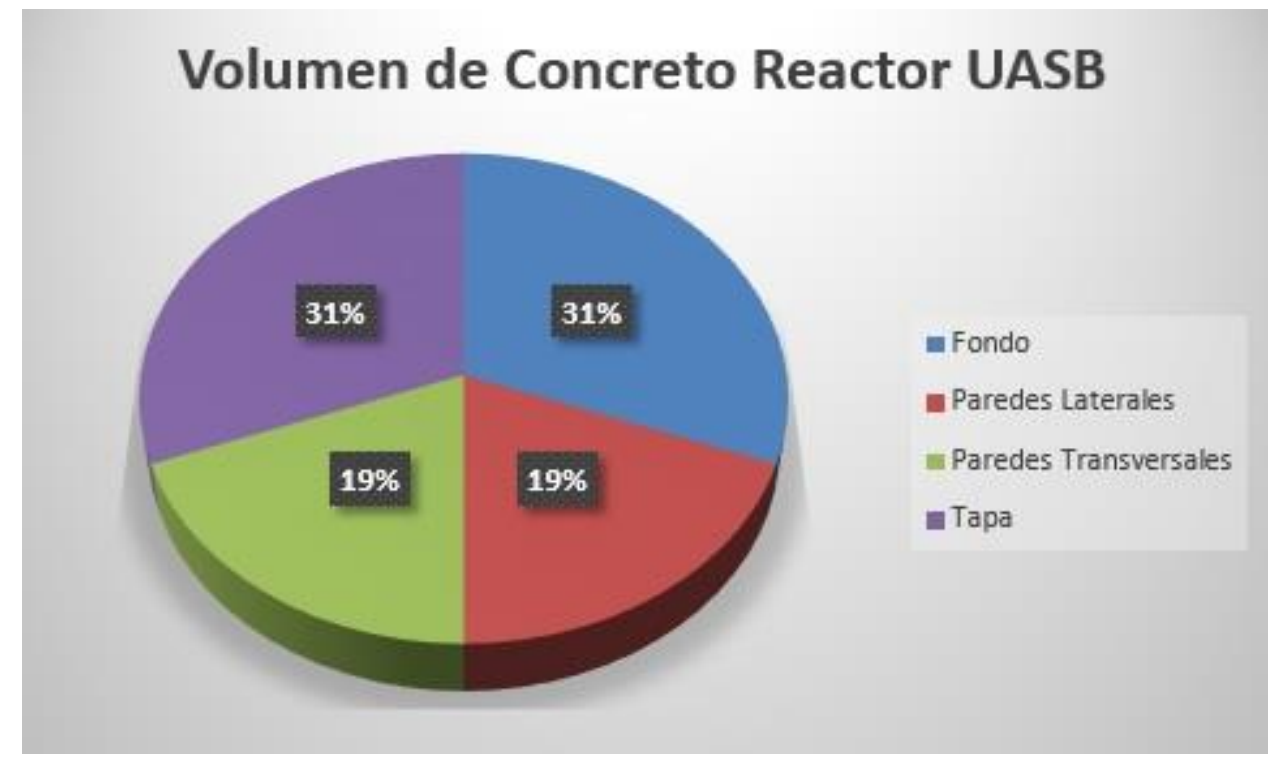

Fuente: Los Autores 
Gráfica 4. Relación del volumen de concreto entre un sistema de Tanque Séptico y un Reactor UASB.

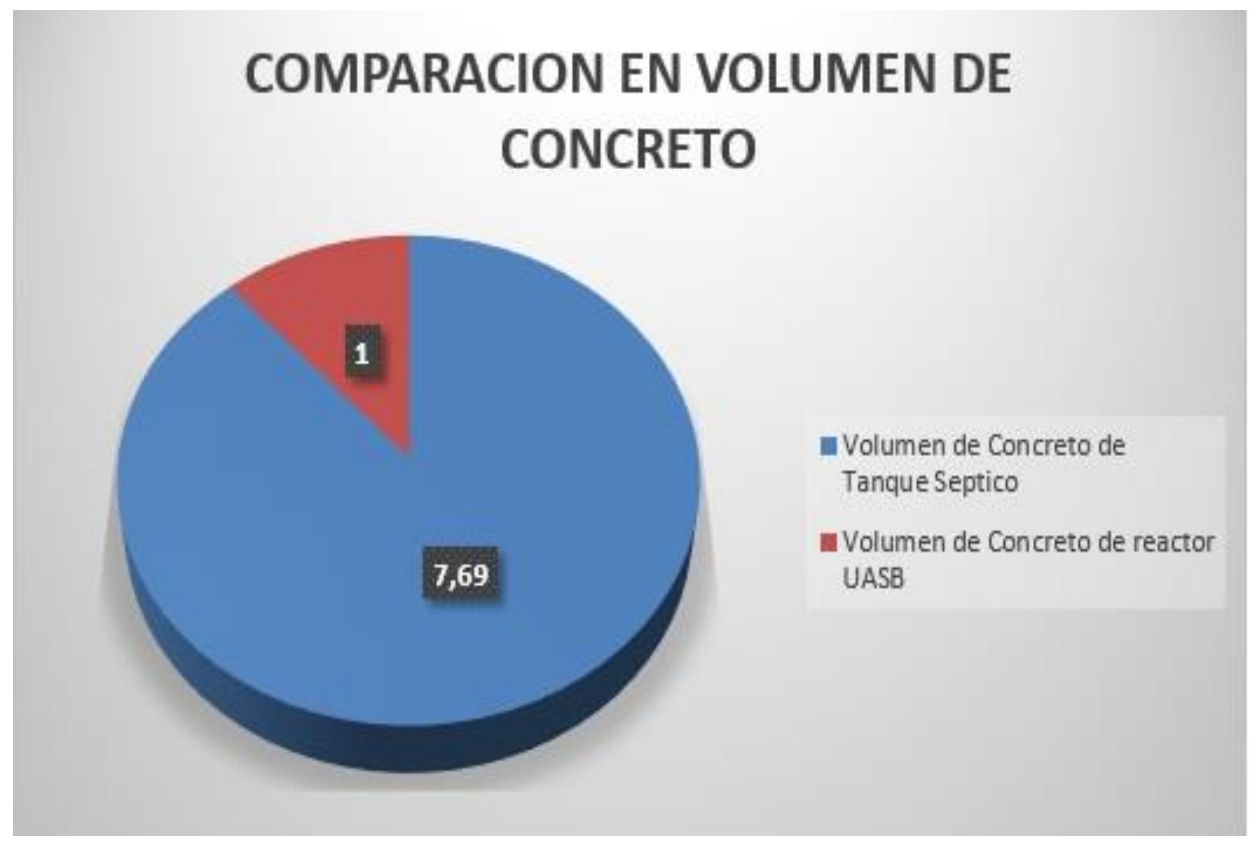

Fuente: Los Autores

\section{Discusión}

De los resultados comparativos a la misma población y para la misma calidad de agua se obtiene lo siguiente: En cuanto a dimensionamiento el tanque séptico resulta ser menos eficiente ya que es 10.2 veces más grande que un reactor UASB en cuanto a tamaño se refiere y en cuanto a volumen de concreto necesita 7.62 veces más que el reactor UASB.

Para poblaciones estudiantiles de mediana a alta densidad donde no existe Sistema de alcantarillado el tanque séptico no resulta ser la solución más eficiente en cuanto a dimensión se refiere, agregando el análisis de Costo Beneficio del reactor UASB que proporciona más ventajas que costos lo cual hace viable su implementación. 


\section{Referencias Bibliográficas}

Ayala Rodrigo y Greby Gonzales (2008). Apoyo Didáctico en la Enseñanza - Aprendizaje de la Asignatura de Plantas de Tratamientos de Aguas Residuales Cochabamba Bolivia.

Conil, P. (2001). La tecnología anaerobia UASB en el tratamiento de las aguas residuales domésticas: 10 años de desarrollo y maduración en América Latina. Waterloo Bélgica: Biotec.

Escalante Rosales Tanques Sépticos, Conceptos Teóricos base y aplicaciones. Revista Tecnología en Marcha. Vol. 18 №2 Especial Pag 26-33

Instituto de Acueductos y Alcantarillados (2006). Normas Técnicas para Aprobación de Planos de los Sistemas de Acueductos y Alcantarillados Sanitarios. IDAAN, Dirección de Ingeniería, Departamento de Estudio y Diseño. Panamá.

Gaviria, C. A. O., Cabrera, C. C. T., \& Losada, L. M. (2014). Arranque de un Reactor UASB para el Tratamiento de Aguas Residuales Domésticas en Condiciones Andino Amazónicas. Revista Facultad de Ciencias Básicas, 10 (2), 170-185.

Lorenzo, Y., \& Obaya, M. C. (2006). La digestión anaerobia y los reactores UASB. Generalidades. ICIDCA. Sobre los Derivados de la Caña de Azúcar, 40 (1), 13-21. Instituto Cubano de Investigaciones de los Derivados de la Caña de Azúcar Ciudad de La Habana, Cuba.

Lozada, P. T. (2012). Perspectivas del tratamiento anaerobio de aguas residuales domésticas en países en desarrollo. Revista EIA, 9 (18), 115-129.

Madera, C. A., Silva, J. P., \& Peña, M. R. (2005). Sistemas combinados para el tratamiento de aguas residuales basados en tanque séptico-filtro anaerobio y humedales subsuperficiales. Revista Ingeniería y Competitividad, 7 (2), 5-10. 
Ministerio de Comercio e Industrias (2000). Reglamento Técnico DGNTI-COPANIT 392000: Descarga de Efluentes Líquidos Directamente a Sistemas de Recolección de Aguas Residuales. Ministerio de Comercio e Industrias Dirección General de Normas y Tecnología Industrial, MICl.

Ministerio de Comercio e Industrias (2019). Reglamento Técnico DGNTI-COPANIT 352019: Descarga de Efluentes Líquidos a Cuerpos y Masas de Aguas Continentales y Marinas. Dirección General de Normas y Tecnología Industrial, MICl.

Organización Panamericana de la Salud (2005). Guía para el Diseño de Tanques Sépticos, Tanques IMHOFF y Lagunas de Estabilización según la Organización Panamericana de la Salud. Peru, Lima.

Organización Panamericana de la Salud (2005). Especificaciones Técnicas para la Construcción de Tanques Sépticos, Tanques IMHOFF y Lagunas de Estabilización según la Organización Panamericana de la Salud. Peru, Lima.

Pickford John, "The design of septic tanks and aqua-privies ", Overseas buildings notes, Overseas Division of the Building Research Establishment, England, 1980.

Salazar-Larrota, L., Uribe-Garcia, L., Gómez-Torres, L., \& Zafra-Mejía, C. (2019). Analysis of the efficiency of UASB reactors in a municipal wastewater treatment plant. DYNA, 86(209), 319-326.

Sosa Gonzalo. (2006). Unidades Alternativas de Saneamiento en Bogotá Dirección de salud pública. Girardot OMS-OPS.

Torres Lozada, P., Rodríguez, J. A., Barba, L. E., Morán, A., \& Narváez, J. (2011). Tratamiento anaerobio de lixiviados en reactores UASB. Revista Científica Ingeniería y Desarrollo, 18 (18), 50-60. 
Unigarro, G. D. J., Zambrano, H. L. R., \& Gallo, S. A. C. (2014). Caracterización y modelación del comportamiento hidráulico de un reactor UASB. Revista EIA, 11 (22), 6775. 